Mirosław JEMIELNIAK

Silesian University of Technology (Politechnika Ślaska)

\title{
MATHEMATICAL MODEL OF OPTIMISATION THE SELECTION OF AVIATION PERSONNEL TO PERFORM FLYING DRILLS
}

\section{Model matematyczny optymalizacji doboru personelu lotniczego do wykonywania ćwiczeń lotniczych}

\begin{abstract}
The report presents the rules of a criterial optimisation of crew selection to execute a specific aviation drill. A typical approach to mathematical analysis has been adopted, describing the problem of verifying and evaluating the flying personnel to execute aviation drills on a particular type of aircraft. Fundamental input data and criteria for potential evaluation of the flight personnel selection for a crew performing a selected task on a given type of aircraft are developed and presented. It was necessary to single out and describe the boundary conditions of this flight crew selection system that determine the system's effectiveness. The report concludes that it is essential to make use of complex systems of management and training completed in military aviation as well as civil.
\end{abstract}

Keywords: selection of flight crews, aviation training, flight security

Streszczenie: W sprawozdaniu przedstawiono zasady kryterialnej optymalizacji doboru personelu do wykonywania określonego ćwiczenia lotniczego. Przyjęto typowe podejście do analizy matematycznej, opisujace problem weryfikowania $i$ oceniania personelu lotniczego pod katem wykonywania ćwiczeń lotniczych na określonym typie statku powietrznego. Opracowano i przedstawiono podstawowe dane wejściowe oraz kryteria stużace potencjalnej ocenie doboru personelu lotniczego do wykonania określonego zadania na danym typie statku powietrznego. Konieczne byto wyodrębnienie i opisanie warunków brzegowych systemu doboru personelu lotniczego, które decyduja o skuteczności systemu. W raporcie stwierdza się, że niezbędne jest wykorzystywanie złożonych systemów zarządzania i szkoleń odbywanych w lotnictwie wojskowym i cywilnym.

Słowa kluczowe: dobór personelu lotniczego, szkolenie lotnicze, bezpieczeństwo lotu 


\section{Introduction}

In the rapidly evolving aviation market, firms are facing pilot shortages to perform flying drills. According to Boeing's report "Pilots \& Technicians outlook"[1] the Asian market has the highest demand for pilots (266,000 vacancies), followed by Europe $(148,000)$ and North America $(212,000)$ respectively. The report "Projection of the number of passengers served and the number of passenger operations in Poland until 2035"[2] ("Projekcja liczby obsłużonych pasażerów oraz liczby operacji pasażerskich w Polsce do roku 2035") published by the Polish Civil Aviation Authority predicted a 15.6\% increase in 2017 in passenger service to $3.4 \%$ in 2035 for a constant increase in air operations; from 408,000 to 698,000 . It has been quickly updated due to an $18 \%$ increase of passengers attended to by airports in Poland in the year the report "Projection" ("Projekcja") was published, making it the second highest increase in the world at the time. The decrease in fully qualified pilots (with the highest ranking license) might force firms to look to different solutions consisting of less qualified personnel and assigning them easier drills. Creating groups of personnel based on the level of training in a logical manner demands creating various selection systems of crews to perform specific tasks, creating training groups and gradually improving their qualifications (trainings to higher ranking authorizations).

\section{Input parameter of the system}

Such a system of selecting personnel to complete specific tasks demands a precise definition. It is invaluable to define the requirements and criteria to verify and select the crews tasked with executing a particular drill on a given type of aircraft.

The input data for the selection of crews to execute a flying drill concerns given types of aircrafts, pilots and their details in the field of flight time, qualifications, possessed topicalities to flights, etc.

Let the set of aircraft types be defined as:

$$
S P=\left\{s p_{i}: i=1,2, \ldots n\right\}
$$

where: $I$ - the next type of aircraft,

$n \quad$ - the number of all the types of aircrafts.

Let the set of type $I$ aircrafts be defined as:

$$
\forall s p_{i} \in S P \quad L\left(s p_{i}\right)=\left\{l_{i}^{m}: m=1,2, \ldots, M\right\}
$$

where: $m$ - the next number of type $I$ aircraft,

$M \quad$ - the number of all type $I$ aircrafts. 
Let the set of pilots for a given type of aircraft $s p_{i}$ be defined as:

$$
\forall s p_{i} \in S P \quad P\left(s p_{i}\right)=\left\{p_{i}^{k}: k=1,2, \ldots, K\right\}
$$

where: $k$ - the next number of a pilot with qualifications for a given type of aircraft $s p_{i}$,

$K \quad$ - number of all pilots qualified for a given type of aircraft $s p_{i}$.

Let the set of types of aviation training for a given type of aircraft $s p_{i}$ be defined as:

$$
\forall s p_{i} \in S P \quad S\left(s p_{i}\right)=\left\{s_{i}^{j}: j=1,2, \ldots, J\right\}
$$

where: $j \quad$ - the next number of a type of aviation training (drill, emergency situation training),

$J \quad$ - number of all aviation trainings (drill) on a given type of aircraft $s p_{i}$.

Let the matrix of allocating a type of aviation training (drill) $s_{i}^{j}$ on given type of aircraft $s p_{i}$ to a given pilot $p_{i}^{k}$ :

$$
\Omega\left(s p_{i}\right)=\left[\begin{array}{cccc}
\omega_{p_{i}^{1}}^{s_{i}^{1}} & \omega_{p_{i}^{2}}^{s_{i}^{2}} & \ldots & \omega_{p_{i}^{1}}^{s_{i}^{J}} \\
\omega_{p_{i}^{2}}^{s_{1}^{2}} & \omega_{p_{i}^{2}}^{s_{i}^{2}} & \ldots & \omega_{p_{i}^{2}}^{s_{i}^{I}} \\
\ldots & \ldots & \ldots & \ldots \\
\omega_{p_{i}^{k}}^{s_{i}^{1}} & \omega_{p_{i}^{k}}^{s_{i}^{2}} & \ldots & \omega_{p_{i}^{k}}^{s_{i}^{l}}
\end{array}\right]=\left[\omega_{p_{i}^{k}}^{s_{i}^{j}}: p_{i}^{k} \in P\left(s p_{i}\right), s_{i}^{j} \in S\left(s p_{i}\right), \omega_{p_{i}^{k}}^{s_{i}^{j}} \in\{0,1\}\right]
$$

Let the matrix of time $T$ of aviation training $S_{i}^{j}$ on a given type of aircraft $s p_{i}$ by a given pilot with qualifications for this type of $p_{i}^{k}$ be defined as:

$$
T\left(s p_{i}\right)=\left[\begin{array}{cccc}
t_{p_{i}^{1}}^{s_{i}^{1}} & t_{p_{i}^{1}}^{s_{i}^{2}} & \ldots & t_{p_{i}^{1}}^{s_{i}^{J}} \\
t_{p_{i}^{2}}^{s_{1}} & t_{p_{i}^{2}}^{s_{i}^{2}} & \ldots & t_{p_{i}^{2}}^{s_{i}^{I}} \\
\ldots & \ldots & \ldots & \ldots \\
t_{p_{i}^{K}}^{s_{1}^{1}} & t_{p_{i}^{K}}^{s_{i}^{2}} & \ldots & t_{p_{i}^{K}}^{s_{i}^{J}}
\end{array}\right]=\left[t_{p_{i}^{k}}^{s_{i}^{j}}: p_{i}^{k} \in P\left(s p_{i}\right), s_{i}^{j} \in S\left(s p_{i}\right), t_{p_{i}^{k}}^{s_{i}^{j}} \in \mathfrak{R}^{+}\right]
$$


where: $t_{p_{i}^{k}}^{s_{j}^{j}} \quad$ - time spent in given training (drill) $s_{i}^{j}$ on a particular type of aircraft $s p_{i}$, by given pilot $p_{i}^{k}$.

Let the index of mastery $W_{o p}\left(p_{i}^{k} ; s_{i}^{j}\right)$ by given pilot $p_{i}^{k}$ of given drill $s_{i}^{j}$ on given type of aircraft $s p_{i}$ be defined as:

$$
W_{o p}\left(p_{i}^{k} ; s_{i}^{j}\right)=\frac{1}{T} \sum_{z=1}^{Z}\left(\begin{array}{c}
t_{i}^{j} \\
p_{i}^{k}
\end{array}\right)_{z}
$$

where: $z \quad$ - the next number of a drill completed $s_{i}^{j}$ by given pilot $p_{i}^{k}$ on given type of aircraft $s p_{i}$,

$Z \quad$ - figure describing how many times a given drill was completed $s_{i}^{j}$ by given pilot $p_{i}^{k}$ on given type of aircraft $s p_{i}$,

$T \quad$ - total time spent by pilot $p_{i}^{k}$ on given type of aircraft $s p_{i}$ :

$$
T=\sum_{b=1}^{B} t_{b}^{s p}+\sum_{c=1}^{C} t_{c}^{s s p_{i}}
$$

where: $t_{b}^{s p_{i}}$ - flight time on given type of aircraft $s p_{i}$ by pilot $p_{i}^{k}$,

$t_{c}^{S S p_{i}}$ - time spent on simulator of given type of aircraft $S S p_{i}$ by given pilot $p_{i}^{k}$.

Let the index of training a given pilot $p_{i}^{k}$ on a given type of aircraft $s p_{i}$ be defined as:

$$
W_{s z}\left(p_{i}^{k}\right)=\frac{T}{T_{n}}
$$

where: $T_{n}-$ complete flight time of given pilot $p_{i}^{k}$.

The comprehensive function of the target criterion is determined by three functions, such as: 


$$
F(X)=\left[F_{1}(X), F_{2}(X), F_{3}(X)\right]
$$

where: $F_{1}(X) \rightarrow \max \quad$ - function defining the maximisation of training the flight personnel (including flight time in simulations),

$F_{2}(X) \rightarrow \max \quad$ - function defining the maximisation of flight time completed in airplanes,

$F_{3}(X) \rightarrow \min \quad$ - function defining the minimisation of operational costs (pilot training).

\section{Criteria evaluating the quality of the flight personnel selection system to perform drills}

Whilst analysing the system of flight personnel selection to perform drills in a given firm, we must adopt evaluation criteria for this system meaning we must adopt optimisation criteria. Assuming that the firm employs a fixed $\Pi_{e k s}^{\omega}$ number of pilots with a given license $\omega$ implicates the optimization criterion, which is the revenue resulting from the work realised by the given number of flight personnel. We are assuming that the firm employs in an established readiness a constant $\Pi_{G T}^{\omega}$ number of flight personnel.

Assuming a constant number of $\Pi_{G T}^{\omega}$, a number of pilots with a given license $\omega$ ready to perform a drill is determined by the fact, that to complete this particular drill, the firms needs to constantly keep a specific number of pilots $\Pi_{G T}^{\omega}$. Increasing the number of pilots on the same stage of training is economically unjustified, because during constant drills, an additional number of pilots does not benefit the firm. On the other hand, decreasing the number of $\Pi_{G T}^{\omega}$ by pilots with a given license $\omega$ ready to perform drills is unacceptable because the firm (enterprise) would not be able to complete all assigned drills.

For an overall number of all $\Pi_{e k s}^{\omega}$ pilots with a given license $\omega$ in the firm, we receive a set number of $\Pi_{G T}^{\omega}$ ready pilots to execute specific drills and a number of $N_{p}^{\omega}$ pilots with a given license $\omega$ situated temporarily outside the firm.

The number of $\Pi_{e k s}^{\omega}$ pilots with a given license $\omega$ will be expressed by an algebraic expression:

$$
\Pi_{e k s}^{\omega}=\Pi_{G T}^{\omega}+\sum_{p=1}^{P} N_{p}^{\omega} \quad \text { for } \quad \forall \omega \in \Omega,
$$

where: $\Omega$ - number of all available classes of pilots in a given firm (enterprise),

$P \quad$ - number of absent pilots situated outside the firm. 


\section{The boundary conditions of the system of flight crew selection to execute drills}

Assuming the existence of the flight crew selection system and the process's two-state property, two states are distinguished: qualifications and expectations i.e. the flight crew awaits for the allocation of a given drill or it carries out drills after qualifying according to the task schedule. Furthermore it is assumed that this flight crew classification system has at its disposal a number of pilots on standby resulting from the constant number of drills necessary for firms to keep the required readiness for executing drills.

While it is assumed that the demand for flights from the side of a given type of pilot's training of given license $\omega$ is determined by the intensity $\alpha_{o}^{\omega}$ of demand for flights of type $o$ for a pilot with license $\omega$, where $o \in 0, \omega \in \Omega$.

The intensity of demand for flights is constant for the system of flight crew selection in time and can be described in the form of an algebraic expression:

$$
\alpha_{o}^{\omega}=\frac{K_{o}^{\omega} \cdot \Pi_{e k s}^{\omega}}{T_{e k s}^{\omega}}=\frac{K_{o}^{\omega} \cdot \Pi_{e k s}^{\omega}}{\frac{E_{o}^{\omega}}{\lambda \omega}+\vartheta_{o}^{\omega}} \quad \text { for } \begin{gathered}
\forall \omega \in \Omega \\
\forall o \in O
\end{gathered},
$$

where: $E_{o}^{\omega} \quad$ - total flight time of personnel flying with given license $\omega$,

$\lambda^{\omega} \quad$ - the mean intensity of usage of the flying personnel with given license $\omega$

$$
\vartheta_{o}^{\omega}=\sum_{r=1}^{R_{o}^{\omega}}\left(\gamma_{o, \omega}^{r} \cdot x_{o, \omega}^{r}+\tau_{o, \omega}^{r} \cdot x_{o, \omega}^{r}\right)
$$

The value of the waiting time for flight completion $\gamma_{o, \omega}^{r}$ of a given type $O$ with employing a $p$ 'th pilot with a given license $\omega$, depends on the efficiency $M_{o, \omega}$ of the system of flight completion. If the efficiency of the system is too small, then the value of waiting time $\gamma_{o, \omega}^{r}$ for the completion of flight type $O$ with employing a $p$ 'th pilot in an aircraft type $\omega$ increases.

For the system of selecting flight crews to perform aviation drills to function properly, the intensity of need to perform a flight must be lower or equal to the efficiency of the system of selecting flight crews to perform tasks (flights), such as:

$$
M_{o, \omega} \geq \Pi_{e k s}^{\omega} \cdot \frac{\sum_{l=0}^{P \omega} K_{l}^{\omega}}{T_{e k s}^{\omega}} \cdot \sum_{p=1}^{P_{o}^{\omega}} \tau_{o, \omega}^{p} \cdot x_{o, \omega}^{p} \geq 0 \text { for } \begin{aligned}
& \forall \omega \in \Omega \\
& \forall o \in O
\end{aligned}
$$




$$
M_{\mathrm{o}, \omega}=\sum_{\mathrm{p}=1}^{\mathrm{P}_{\mathrm{o}}^{\omega}} \mathrm{m}_{\mathrm{o}, \omega}^{\mathrm{p}} \cdot \mu_{\mathrm{o}, \omega}^{\mathrm{p}} \cdot \mathrm{x}_{\mathrm{o}, \omega}^{\mathrm{p}}
$$

where:

$\mu_{o, \omega}^{p} \in \mathfrak{R}^{+}$is the efficiency of the firm performing the o'th type of flight for a pilot with a given license $\omega$ employing a p'th pilot,

$m_{o, \omega}^{p} \in \mathfrak{R}^{+}$is the number of pilots performing the o'th flight of a given type for a given pilot license $\omega$ using a p'th pilot.

If the condition (12) was not met, then the value of entry streams of the system of flight crew selection to execute drills (flights) $o$ 'th type, pilots with given license $\omega$ would be greater than the value of the stream of pilots leaving the given system. For such circumstances the number of pilots possessing the license $\omega$ located in the system increases. Consequently, it creates waiting lines which increases the probability that the firm will fail to complete the assigned drills.

It is essential to define $m_{o, \omega}$, for which the waiting time to perform a flight $\gamma_{o, \omega}$ for $\forall o \in O$ is null. This value will be calculated for the maximum demand intensity to perform a flight from the following algebraic expression:

$$
m_{o, \omega}=\frac{\Pi_{e k s}^{\omega}}{\sum_{p=1}^{P o} \mu_{o, \omega}^{p} \cdot x_{o, \omega}^{p}} \cdot \sum_{o=1}^{O} \sum_{p=1}^{P_{o}^{\omega}} \frac{1}{\theta_{l}^{\omega}+\sum_{l=1}^{o} \tau_{l, \omega}^{p} \cdot x_{l, \omega}^{p}} \quad \text { for } \quad \begin{gathered}
\forall \omega \in \Omega \\
\forall o \in O
\end{gathered}
$$

To determine the value of $m_{o, \omega}$ we reject the condition that this value must be an integer. We will also modify the condition of balancing the demand to perform a flight and the service possibilities of elements in the system (efficiency) to an equality:

$$
\alpha_{o}^{\omega}=\sum_{p=1}^{P_{o}^{\omega}} m_{\mathrm{o}, \omega}^{p} \cdot \mu_{\mathrm{o}, \omega}^{p} \cdot x_{o, \omega}^{p} \quad \text { for } \begin{gathered}
\forall \omega \in \Omega \\
\forall o \in O
\end{gathered}
$$

so $\gamma_{o, \omega}=0$.

The numbers $m_{o, \omega} \in \mathfrak{R}^{+}$are interpreted as the values of the coefficients describing the itinerancy of particular elements of the flight crew selection system to perform drills.

The working time $T_{e k s}^{\omega}$ of the flight personnel type $\omega$ is the sum of the following components:

$$
T_{e k s}^{\omega}=\theta_{0}^{\omega}+\sum_{O=1}^{O_{\omega}} K_{o}^{\omega} \cdot \vartheta_{o}^{\omega} \quad \text { for } \quad \forall \omega \in \Omega
$$


where: $\theta_{0}^{\omega} \in \mathfrak{R}^{+}$- number interpreting the time of effective work completed by the flight personnel type $\omega$ in the assigned period,

$\vartheta_{o}^{\omega} \in \mathfrak{R}^{+}$- number interpreting the time duration (completion) o'th flight of flight personnel type $\omega$;

$$
\vartheta_{o}^{\omega}=\sum_{o=1}^{P_{o}^{\omega}}\left(\gamma_{o, \omega}^{p} \cdot x_{o, \omega}^{p}+\tau_{o, \omega}^{p} \cdot x_{o, \omega}^{p}\right),
$$

where: $\gamma_{o, \omega}^{p} \in \mathfrak{R}^{+}$- number interpreting the waiting time for o'th flight employing $\mathrm{p}$ 'th pilot possessing the license $\omega$,

$K_{o}^{\omega} \in \mathfrak{R}^{+}$- number of o-type flight performed by the flight personnel type $\omega$ in the assigned period.

After an adequate conversion, the time of all flights $T_{e k s}^{\omega}$ of the flight personnel $\omega$ can be defined in the following expression:

$$
T_{e k s}^{\omega}=\theta_{0}^{\omega}+\sum_{o=1}^{O_{\omega}} \sum_{p=1}^{P_{o}^{\omega}}\left(\gamma_{\mathrm{o}, \omega}^{p} \cdot x_{\mathrm{o}, \omega}^{p}+\tau_{\mathrm{o}, \omega}^{p} \cdot x_{\mathrm{o}, \omega}^{p}\right) \cdot \sum_{l=o}^{O} K_{l}^{\omega} \quad \text { for } \forall \omega \in \Omega .
$$

Substituting (17) into the formula (12), gives us:

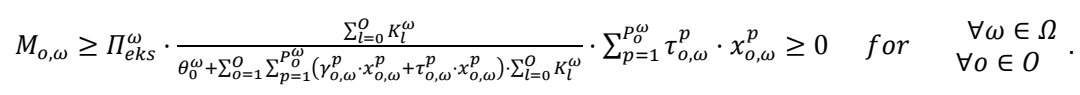

Then substituting (17) into the equation (11), we obtain:

$$
\begin{gathered}
\alpha_{o}^{\omega}=\frac{K_{o}^{\omega} \cdot \Pi_{e k s}^{\omega}}{\theta_{o}^{\omega}+\sum_{o=1}^{o} \sum_{p=1}^{P_{o}^{\omega}}\left(\gamma_{o, \omega}^{p} \cdot x_{o, \omega}^{p}+\tau_{o, \omega}^{p} \cdot x_{o, \omega}^{p}\right) \cdot \sum_{l=0}^{o} K_{l}^{\omega}}=\frac{K_{o}^{\omega} \cdot \Pi_{e k s}^{\omega}}{\frac{E_{o}^{\omega}}{\lambda^{\omega}}+\sum_{o=1}^{o} \sum_{p=1}^{P_{o}^{\omega}}\left(\gamma_{o, \omega}^{p} \cdot x_{o, \omega}^{p}+\tau_{o, \omega}^{p} \cdot x_{o, \omega}^{p}\right) \cdot \sum_{l=0}^{o} K_{l}^{\omega}} \\
\text { for } \forall \omega \in \Omega \\
\forall o \in O
\end{gathered}
$$

The execution time of $o$-th flights, where $o \in O$, for personnel flying with license $\omega, \omega \in \Omega$ is equal to:

$$
\begin{aligned}
y_{p, \omega} & =\frac{\Pi_{e s s}^{\omega} \cdot \Sigma_{l=o}^{O} K_{l}^{\omega}}{\theta_{0}^{\omega}+\sum_{o=1}^{O} \Sigma_{p=1}^{P_{o}}\left(\gamma_{o, \omega}^{p} \cdot x_{o, \omega}^{p}+\tau_{o, \omega}^{p} \cdot x_{o, \omega}^{p}\right) \cdot \Sigma_{l=o}^{O} K_{l}^{\omega}} \cdot \sum_{p=1}^{P_{o}^{\omega}} \tau_{o, \omega}^{p} \cdot x_{o, \omega}^{p} \quad \text { for } \quad \begin{array}{r}
\forall \omega \in \Omega \\
\quad \forall 0 \in O
\end{array} \\
y_{p, \omega} & \geq 0 .
\end{aligned}
$$


To ensure the completion of all types of flights for the flight personnel possessing the license $\omega, \omega \in \Omega$, these flights cannot exceed the efficiency of the flight execution system, such as:

$$
\begin{gathered}
\frac{\Pi_{e k s}^{\omega} \cdot \sum_{l=o}^{o} K_{l}^{\omega}}{\theta_{0}^{\omega}+\sum_{o=1}^{o} \sum_{p=1}^{P_{o}^{\omega}}\left(\gamma_{o, \omega}^{p} \cdot x_{o, \omega}^{p}+\tau_{o, \omega}^{p} \cdot x_{o, \omega}^{p}\right) \cdot \sum_{l=o}^{o} K_{l}^{\omega}} \cdot \sum_{p=1}^{P_{o}^{\omega}} \tau_{o, \omega}^{p} \cdot x_{o, \omega}^{p} \leq \frac{\Pi_{e k s}^{\omega}}{\sum_{o=1}^{P_{o}^{\omega}} \mu_{o, \omega}^{p} \cdot x_{o, \omega}^{p}} \cdot \sum_{l=o}^{o} \sum_{p=1}^{P_{o}^{\omega}} \frac{1}{\theta_{l}^{\omega}+\sum_{l=1}^{o} \tau_{l, \omega}^{p} \cdot x_{l, \omega}^{p}} \\
\text { for } \begin{array}{c}
\forall \omega \in \Omega \\
\forall o \in O
\end{array} .
\end{gathered}
$$

Every $o$-th flight of the flying personnel pilot licensed $\omega$ can be completed with the usage of one pilot license from the set of all available pilots $P_{o}^{\omega}$, such as:

$$
\sum_{p=1}^{P_{o}^{\omega}} x_{o, \omega}^{r}=1 \text { for } \begin{aligned}
& \forall \omega \in \Omega \\
& \forall o \in O
\end{aligned}
$$

Ultimately it is important to point out that the presented dependencies lead to a solution of a multicriterial system of flight crew selection to perform drills on a given type of aircraft which comes down to minimalizing the criterium function on the set of acceptable solutions. The solution of this problem optimisation leads to the determination of an optimal structure of a flight crew selection system to perform tasks on a given type of aircraft. This allows the determination of the coefficient of flight crew's readiness $\eta^{*}$. It is defined as the ratio of the number of flying personnel needed to keep a state of readiness $\Pi_{G T}$ to the number of flying personnel employed by the organisational unit $\Pi_{e k s}^{*}$ :

$$
\eta^{*}=\frac{\Pi_{G T}}{\Pi_{e k s}^{*}}
$$

\section{Conclusion}

The analysis illustrates that it is possible to designate pilots of various states of training (possessed licences) to safely perform aviation drills. Nevertheless, it is essential to develop appropriate operational procedures to manage flight personnel. This procedures are based on mathematical models that should be the foundation to develop computer based systems of management and flight crew training support. 
These computer based systems supervised by a trained staff will become the basis for a modern aviation company management. They will also provide an appropriate flight crew selection system relying on possessed qualifications adequate to the difficulty the task assigned.

This management system will be a tool ready for changes in the dynamic market of aviation and expensive flight personnel training in adequate quantities for the needs of the enterprise. The dynamic progress of modern aviation constructions demands a constant development of qualifications and skills. To achieve that, modern systems of aviation training supporting the exploitation and utilisation of modern solutions for aviation technology are required.

To rationally approach the processes of planning, organising and managing aviation on every organisational level, the management board in charge of flying drills execution and flying crew training stands in need of access to up-to-date information for the system to operate efficiently

\section{References}

1. The 2019 Boeing Pilot \& Technician Outlook. Pilot Outlook by Region. New Pilot Demand 2019-2038.

2. Projection of the number of passengers served and the number of passenger operations in Poland until 2035. Polish Civil Aviation Authority Projection_2017pdf 30/10/2017. 